\title{
Reinstatement of Alcohol-Seeking Behavior by Drug-Associated Discriminative Stimuli after Prolonged Extinction in the Rat
}

\author{
Simon N. Katner, Ph.D., Jennifer G. Magalong, B.S., and Friedbert Weiss, Ph.D.
}

Clinical observations suggest that stimuli associated with the availability or consumption of ethanol can evoke subjective feelings of craving and trigger episodes of relapse in abstinent alcoholics. To study the motivational significance of alcohol-related environmental cues experimentally, the effects of discriminative stimuli previously predictive of alcohol availability on the reinstatement of ethanol-seeking behavior were examined. Wistar rats were trained to lever-press for $10 \%(w / v)$ ethanol or water in the presence of distinct auditory cues. The rats were then subjected to an extinction phase where lever presses had no scheduled consequences. After extinction, the animals were exposed to the respective auditory cues without the availability of ethanol or water. Neither the ethanol $\left(S_{A}{ }^{+}\right)$nor water-associated $\left(S_{A}{ }^{-}\right)$ auditory cue increased responding over extinction levels. In contrast, subsequent presentation of an olfactory cue associated with ethanol $\left(S_{O}{ }^{+}\right)$, but not a water-associated $\left(S_{O}{ }^{-}\right)$cue significantly reinstated lever pressing behavior in the absence of the primary reinforcer. Moreover, responding elicited by the concurrent presentation of the $S_{O}{ }^{+}$and $S_{A}{ }^{+}$ was selectively attenuated by the opiate antagonist naltrexone $(0.25 \mathrm{mg} / \mathrm{kg} ; \mathrm{sc})$. The results suggest that ethanol-associated cues can reinstate extinguished ethanolseeking behavior in rats, but that the efficacy of these stimuli may be modality-specific. In addition, the present procedures may be useful for studying neurobiological mechanisms of alcohol-seeking behavior and relapse.

[Neuropsychopharmacology 20:471-479, 1999] (C) 1999 American College of Neuropsychopharmacology. Published by Elsevier Science Inc.
KEY WORDS: Ethanol; Self-administration; Discriminative stimulus; Naltrexone; Rats; Craving; Relapse

Environmental stimuli associated with the positive reinforcing actions of drugs of abuse have long been thought to have an important role in triggering the return to drug use (i.e., relapse) in abstinent individuals (Wikler 1948). There is now ample evidence that conditioned stimuli associated with the availability or consumption of abused drugs enhance subjective feelings

From the Scripps Research Institute, Department of Neuropharmacology, La Jolla, California

Address correspondence to: Simon N. Katner, The Scripps Research Institute, Department of Neuropharmacology, 10550 N.

Torrey Pines Road, CVN-15, La Jolla, CA 92037.

Received March 25, 1998; accepted August 18, 1998 of craving and the motivation to engage in drug-taking behavior in humans (Childress et al. 1987a, 1987b, 1988; O'Brien et al. 1990, 1992; Ehrman et al. 1992; Kranzler and Bauer 1992; Robbins and Ehrman 1992). For example, abstinent alcohol users exposed to a bar-like environment worked (i.e., pressed a button which dispensed alcohol) harder to acquire alcohol and showed greater subjective and physiological responses than those exposed to a neutral setting (Ludwig et al. 1974). Similarly, abstinent opiate-dependent subjects reported increased craving in response to the presentation of drug-related stimuli compared to methadonemaintained patients (Childress et al. 1987a).

Drug-related stimuli can modify drug-seeking behavior in animals as well. Behavioral tests involving acquisition, extinction, and reinstatement of operant respond- 
ing have demonstrated that stimuli associated with psychostimulant and opiate reinforcement have conditioned reinforcing effects in rats and monkeys (Schuster and Woods 1968; Davis and Smith 1974; Robbins 1978; de Wit and Stewart 1981). For example, the presentation of visual stimuli previously associated with morphine reinforcement produced increases in response rates during extinction conditions in monkeys (Schuster and Woods, 1968). Similarly, an auditory stimulus (i.e., a tone) that had been associated with cocaine infusions transiently increased the tendency to reinitiate responding during extinction in rats (de Wit and Stewart 1981).

The behavioral effects of ethanol-associated environmental stimuli in animals are less well understood. Ethanol, like other drugs of abuse, can act as a reinforcer in rats; it is possible, then, that stimuli linked to the rewarding effects of ethanol can elicit drug-seeking behavior as well. Moreover, understanding the contingencies and conditions under which alcohol-related environmental stimuli reliably elicit ethanol-seeking behavior may prove helpful in elucidating the neurobiological mechanisms underlying relapse. Therefore, the present study sought to determine whether stimuli associated with ethanol availability can reinstate alcohol-seeking behavior after extinction. Specifically, the goals were: 1) to examine the effects of discriminative stimuli signaling the availability of ethanol versus water on responding at a lever previously associated with the delivery of these reinforcers; and 2) to examine the effect of naltrexone, an opiate antagonist known to inhibit alcohol craving and relapse in humans (O'Malley et al. 1992; Volpicelli et al. 1992, 1995; Davidson et al. 1996), on the efficacy of these cues to reinstate ethanol-seeking behavior.

\section{METHODS}

\section{Subjects}

Twenty-four male Wistar rats (Charles River Co., Kingston, NY) weighing 440-600 grams at the time of testing were used. Rats were housed in groups of three in a temperature and humidity controlled vivarium on a reverse 12-hour light/dark cycle (on, 6:00 p.m.; off, 6:00 a.m.). All training and experimental sessions were conducted during the dark phase of the cycle, five days a week. Standard laboratory rat chow and water were available ad libitum in the home cage, except as noted in "Oral Ethanol Self-Administration" (see below). All experimental procedures were carried out in strict accordance with the National Institutes of Health Guide for the Care and Use of Laboratory Animals.

\section{Self-Administration Apparatus}

Training and testing were conducted in standard operant chambers (Coulborn Instruments, Allentown, PA) located in sound-attenuating cubicles equipped with exhaust fans as previously described (Weiss et al. 1993). Each chamber was equipped with a drinking reservoir (volume capacity: $0.15 \mathrm{ml}$ ) positioned four $\mathrm{cm}$ above the grid floor in the center of the front panel of the chamber, and a retractable lever, located three $\mathrm{cm}$ to the right of the drinking receptacle. The lever required a $10^{-2} \mathrm{~N}$ force to register a response, which resulted in the delivery of $0.1 \mathrm{ml}$ of fluid (either ethanol or water). Auditory stimuli were presented via a speaker located on the front panel above the drinking receptacle. A microcomputer controlled the delivery of fluids, presentation of auditory stimuli, and recording of behavioral data.

\section{Oral Ethanol Self-Administration}

During the initial three days of training, the rats were placed on a fluid restriction schedule limiting water availability to $2 \mathrm{hrs} /$ day in order to facilitate acquisition of operant responding for a liquid reinforcer. During this time, rats were permitted to lever-press for a $0.2 \%(\mathrm{w} / \mathrm{v})$ saccharin solution on a fixed-ratio 1 schedule of reinforcement, throughout daily 30-minute sessions. During all subsequent training and testing, water was freely available in the home cage. After successful acquisition of responding for saccharin, rats were trained to orally self-administer ethanol using a modification of the sucrose-fading procedure (Samson 1986) that employed saccharin instead of sucrose to initiate ethanol self-administration as previously described (Weiss et al. 1993). During the first six days of training, rats were allowed to lever-press for a $5.0 \%(\mathrm{w} / \mathrm{v})$ ethanol solution containing $0.2 \%$ saccharin $(\mathrm{w} / \mathrm{v})$. Starting on day seven, the concentration of ethanol was gradually increased from $5.0 \%$ to $8.0 \%$ and finally to $10.0 \%$ $(w / v)$, while the concentration of saccharin was correspondingly decreased to zero percent.

\section{Behavioral Training Procedures}

To establish discriminative stimuli ( $\left.\mathrm{S} \Delta^{\prime} \mathrm{s}\right)$ predictive of ethanol versus water availability, two distinct auditory cues were presented during the ethanol and water selfadministration sessions. The $\mathrm{S} \Delta$ for ethanol $\left(\mathrm{S}_{\mathrm{A}}^{+}\right)$consisted of a series of regular intermittent beeps $(7 \mathrm{kHz} ; 70$ $\mathrm{dB})$, while the $\mathrm{S} \Delta$ associated with the availability of water $\mathrm{S}_{\mathrm{A}}^{-}$) was a white noise $(70 \mathrm{~dB})$. The $S \Delta^{\prime}$ 's were introduced two days after rats had begun to press for $10 \%$ ethanol during the training phase. The respective $S \Delta$ 's were presented concurrently with the extension of the lever into the operant chamber and remained present throughout each ethanol or water self-administration session. After 14 days of ethanol self-administration training, ethanol and water sessions were alternated daily. In order to minimize possible effects of stress and 
behavioral arousal due to the transfer of the animals from their home cages to the self-administration chambers, a 20-min waiting period was gradually introduced during the early days of the conditioning phase. This waiting period elapsed after the animals had been placed into the self-administration chambers before ethanol or water was made available by extension of the lever, and no auditory cues were presented during this period. Daily discrimination training sessions continued until the rats attained stable levels of responding for $10 \%(\mathrm{w} / \mathrm{v})$ ethanol and water. At this time animals were subjected to daily extinction sessions during which lever presses activated the syringe pump but did not result in the delivery of ethanol, water, or presentation of the corresponding $S \Delta$ 's. The extinction criterion was 5 or fewer lever presses per session for 3 consecutive days. It should be noted that "extinction" in this case was selective in the sense that lever pressing behavior was extinguished in the absence of the $S \Delta^{\prime}$ s.

\section{Reinstatement Testing with Auditory Discriminative Stimuli}

Once the extinction criterion was reached, the rats were divided into two groups. Animals were placed in operant chambers and lever pressing behavior was examined. One group $(n=12)$ was presented non-contingently with the $\mathrm{S}_{\mathrm{A}}{ }^{+}$and the other $(\mathrm{n}=12)$ with the $\mathrm{S}_{\mathrm{A}}{ }^{-}$ during 30-min sessions for three consecutive days. Lever presses were recorded but had no scheduled consequence, except that the pump was activated with each lever press (but did not result in the delivery of a reinforcer).

\section{Reinstatement Testing with Olfactory Discriminative Stimuli}

Olfactory stimuli associated with ethanol versus water availability may have greater salience than auditory cues in rats. To examine this possibility, the rats were divided into four groups ( $n=6$ /group) after completion of reinstatement testing with the auditory cues. As olfactory $S \Delta^{\prime} \mathrm{s}, 5 \mathrm{ml}$ of either $10 \%$ ethanol $\left(\mathrm{S}_{\mathrm{O}}{ }^{+}\right)$or water $\left(\mathrm{S}_{\mathrm{O}}{ }^{-}\right)$were squirted into the bedding of the operant chambers immediately prior to each test session. In addition, the auditory $\mathrm{S} \Delta$ 's associated with ethanol $\left(\mathrm{S}_{\mathrm{A}}{ }^{+}\right)$ or water $\left(\mathrm{S}_{\mathrm{A}}^{-}\right)$availability were presented during some of the reinstatement test sessions such that each of the four groups was exposed to the following stimulus conditions in a random order: 1) $\mathrm{S}_{\mathrm{O}}^{+}$;2) $\mathrm{S}_{\mathrm{A}}{ }^{+} \mathrm{S}_{\mathrm{O}}^{+}$; 3) $\mathrm{S}_{\mathrm{O}}^{-}$; and 4) $\mathrm{S}_{\mathrm{A}}{ }^{-} \mathrm{S}_{\mathrm{O}}{ }^{-}$. Responding in the presence of these discriminative stimuli was recorded. As in the previous test, the only consequence of responding was activation of the pump. The bedding was changed and bedding trays were thoroughly cleaned between sessions.

\section{Effect of Naltrexone on Reinstatement of Responding}

To examine the effects of naltrexone on behavior elicited by ethanol-associated cues, rats were divided into two groups ( $n=12$ /group) after completion of reinstatement testing with the olfactory cues. These tests were performed over a four day period under the following conditions: on the first and second days animals were presented with the $\mathrm{S}_{\mathrm{A}}{ }^{+} \mathrm{S}_{\mathrm{O}}{ }^{+}$, and on the third and fourth days animals were presented with the $\mathrm{S}_{\mathrm{A}}{ }^{-} \mathrm{S}_{\mathrm{O}}{ }^{-}$. On the first and third days of testing, one group of animals was injected with naltrexone $(0.25 \mathrm{mg} / \mathrm{kg}$; SC) while the other received saline $30 \mathrm{~min}$ prior to the beginning of the test session. No drugs were administered on the second and fourth days of testing (see Table 1 for schematic).

\section{Data Analysis}

Responses during the conditioning phase and reinstatement testing with naltrexone were analyzed for differences between groups by two-way mixed-factorial analysis of variance (ANOVA). Responses during the auditory and olfactory reinstatement tests were analyzed by a one-way ANOVA with repeated measures. Significant differences among individual treatment conditions in the olfactory reinstatement test were determined by Fisher's LSD post-hoc comparisons.

\section{RESULTS}

\section{Ethanol Self-Administration Training}

The sweet solution fading procedure was completed within 18 days. The mean ( \pm SEM) number of responses for $10 \%$ ethanol (without saccharin) was $25 \pm$ 2.5 at the end of this training phase. Self-administration training for $10 \%$ ethanol was then continued for another 14 days. During this time, rats developed stable levels of responding with a mean ( \pm SEM) response rate of $31 \pm 2.4$ as measured over the last four days of this phase. This corresponded to mean ( \pm SEM) ethanol intake of $0.71 \pm 0.04 \mathrm{~g} / \mathrm{kg}$.

Table 1. Schematic of the Procedure Used to Examine the Effects of Naltrexone on the Reinstatement of Responding Elicited by Ethanol- and Water-Associated $\mathrm{S} \Delta \mathrm{s}$

\begin{tabular}{lcccc}
\hline & Day 1 & Day 2 & Day 3 & Day 4 \\
\hline Sal Gp: & Sal/ $/ \mathrm{S}_{\mathrm{A}}{ }^{+} \mathrm{S}_{\mathrm{O}}^{+}$ & $\mathrm{S}_{\mathrm{A}}{ }^{+} \mathrm{S}_{\mathrm{O}}{ }^{+}$ & $\mathrm{Sal} \mathrm{S}_{\mathrm{A}}{ }^{-} \mathrm{S}_{\mathrm{O}}{ }^{-}$ & $\mathrm{S}_{\mathrm{A}}{ }^{-} \mathrm{S}_{\mathrm{O}}{ }^{-}$ \\
Nal Gp: & $\mathrm{Nal} / \mathrm{S}_{\mathrm{A}}{ }^{+} \mathrm{S}_{\mathrm{O}}{ }^{+}$ & $\mathrm{S}_{\mathrm{A}}{ }^{+} \mathrm{S}_{\mathrm{O}}{ }^{+}$ & $\mathrm{Nal} / \mathrm{S}_{\mathrm{A}}{ }^{-} \mathrm{S}_{\mathrm{O}}{ }^{-}$ & $\mathrm{S}_{\mathrm{A}}{ }^{-} \mathrm{S}_{\mathrm{O}}{ }^{-}$ \\
\hline
\end{tabular}

Abbreviations: $\mathrm{S}_{\mathrm{A}}{ }^{+} \mathrm{S}_{\mathrm{O}}^{+}$, ethanol-associated discriminative stimuli; $\mathrm{S}_{\mathrm{A}}{ }^{-} \mathrm{S}_{\mathrm{O}}{ }^{-}$, water-associated discriminative stimuli; Sal, saline; Nal, naltrexone; Gp, group. 


\section{Training Phase}

During the training phase, animals developed a clear and significant discrimination between ethanol and water (Figure 1) by increasing responding for ethanol and decreasing responding for water over time, as reflected by a main effect of "reinforcer" $[\mathrm{F}(1,46)=10.1 ; p<.01]$ and a significant interaction between "reinforcer" and "time" $[\mathrm{F}(10,46)=12.1 ; p<.01]$. In addition, the animals developed stable baseline levels of responding for both ethanol and water with a mean ( \pm SEM) number of lever presses of $32.5 \pm 2.6$ for ethanol and $16.0 \pm 2.7$ for water over the last four sessions.

\section{Extinction Phase}

During the first day of extinction, rats responded $33 \pm$ 3.1 times on average (Figure 1). After the first day of extinction, however, lever pressing extinguished rapidly, and all rats reached the extinction criterion ( 5 or fewer lever presses per session for 3 consecutive days) after a total of 13 days.

\section{Reinstatement Phase: Auditory Discriminative Stimuli}

The auditory discriminative stimuli failed to reinstate responding. The mean $( \pm$ SEM) number of responses over a period of three days was $2.7 \pm 0.8$ in rats presented with the $\mathrm{S}_{\mathrm{A}}{ }^{+}$, and $3.0 \pm 1.2$ in rats exposed to the $\mathrm{S}_{\mathrm{A}}^{-}$(Figure 1). By comparison, mean ( \pm SEM) extinction responses during the last three days of the extinction phase were $2.8 \pm 0.5$. No significant statistical differences were found between responding under the $\mathrm{S}_{\mathrm{A}}{ }^{+}$ and $\mathrm{S}_{\mathrm{A}}{ }^{-}$conditions $[\mathrm{F}(1,23)=0.1 ; \mathrm{NS}]$.

\section{Reinstatement Phase: Olfactory Discriminative Stimuli}

In contrast to the auditory cues, the olfactory discriminative stimuli produced a robust reinstatement of responding. These stimuli, alone or in combination with the auditory cues, significantly increased mean $( \pm$ SEM) responding from $2.8 \pm 0.5$ (during extinction) to $7.5 \pm$ $1.1\left(\mathrm{~S}_{\mathrm{O}}^{+}\right.$alone $)$and $9.4 \pm 1.3\left(\mathrm{~S}_{\mathrm{A}}{ }^{+} \mathrm{S}_{\mathrm{O}}^{+}\right)$. The water-associated discriminative stimuli failed to increase respond-

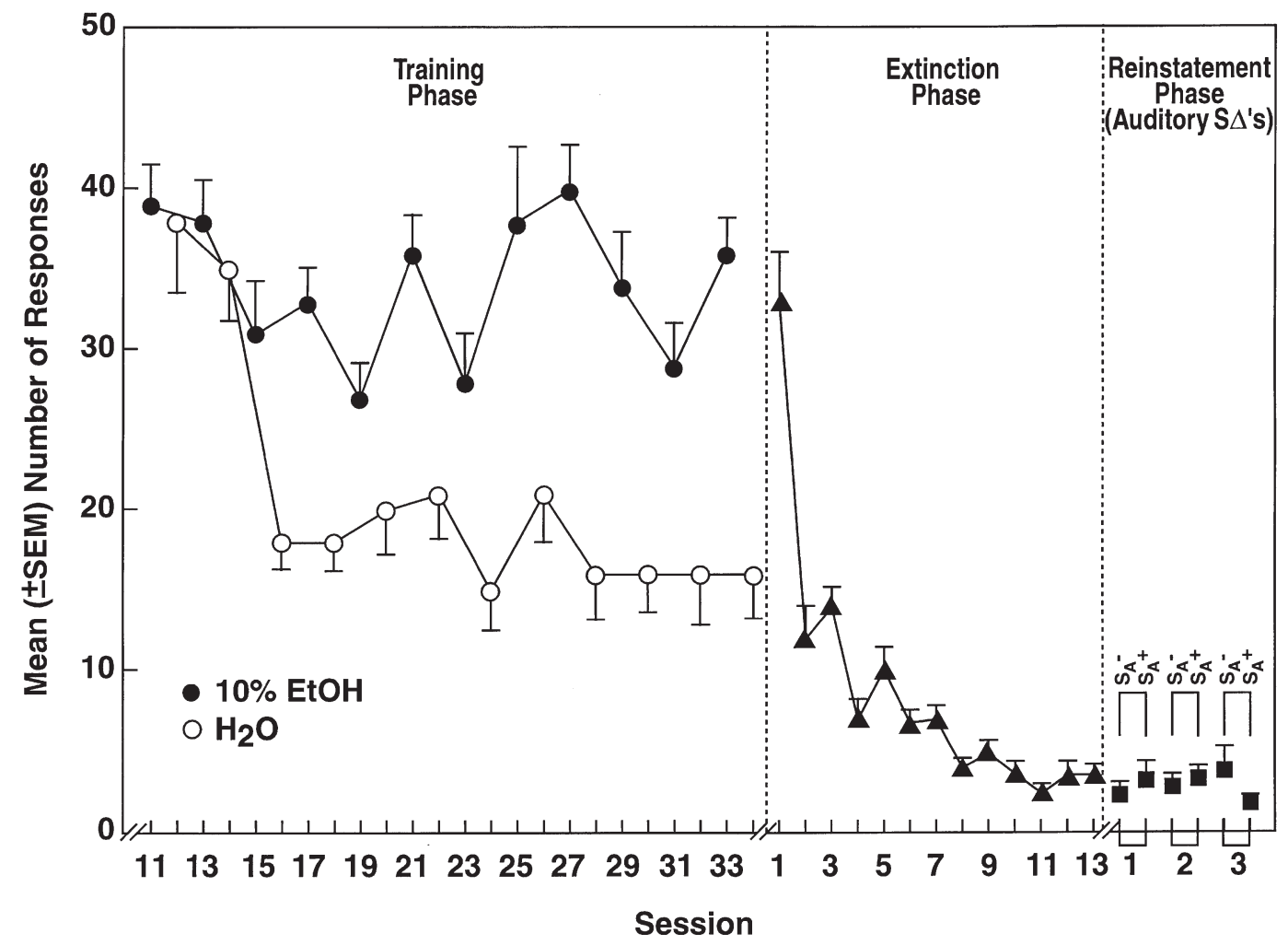

Figure 1. Mean ( \pm SEM) lever presses per 30-min session during training, extinction, and reinstatement (auditory cues) phases in male Wistar rats $(n=24)$. Training phase: during daily alternating ethanol or water self-administration sessions, animals were presented with discrete auditory stimuli: the $\mathrm{S}_{\mathrm{A}}{ }^{+}$during ethanol sessions and the $\mathrm{S}_{\mathrm{A}}{ }^{-}$during water sessions. Animals showed clear behavioral discrimination between ethanol and water at the end of this phase. Extinction Phase: responding ceased rapidly, and all rats reached the extinction criterion within 13 days. Reinstatement phase: the auditory discriminative stimuli failed to increase responding over extinction levels. 
ing $\left[4.2 \pm 0.7\left(\mathrm{~S}_{\mathrm{O}}^{-}\right)\right.$and $\left.4.2 \pm 0.9\left(\mathrm{~S}_{\mathrm{A}}^{-} \mathrm{S}_{\mathrm{O}}^{-}\right)\right]$, and response rates remained within the extinction criterion (Figure 2). There was a significant main effect of "treatment" on responding $[\mathrm{F}(4,92)=9.5 ; p<.01]$ such that under the $\mathrm{S}_{\mathrm{O}}{ }^{+}$and $\mathrm{S}_{\mathrm{A}}{ }^{+} \mathrm{S}_{\mathrm{O}}{ }^{+}$conditions, levels of responding were significantly higher than baseline levels during extinction. Post-hoc comparisons revealed significant $(p<.05)$ differences between the following conditions: "extinction baseline" vs. $\mathrm{S}_{\mathrm{O}}^{+}$and $\mathrm{S}_{\mathrm{A}}{ }^{+} \mathrm{S}_{\mathrm{O}}{ }^{+}$; $\mathrm{S}_{\mathrm{O}}{ }^{+}$vs. $\mathrm{S}_{\mathrm{O}}{ }^{-}$and $\mathrm{S}_{\mathrm{A}}{ }^{-} \mathrm{S}_{\mathrm{O}}{ }^{-}$; and $\mathrm{S}_{\mathrm{A}}{ }^{+} \mathrm{S}_{\mathrm{O}}{ }^{+}$vs. $\mathrm{S}_{\mathrm{O}}{ }^{-}$and $\mathrm{S}_{\mathrm{A}}{ }^{-} \mathrm{S}_{\mathrm{O}}{ }^{-}$, confirming that the ethanol olfactory $\mathrm{S} \Delta$ effectively reinstated lever pressing behavior in comparison to levels of responding under baseline extinction conditions.

\section{Effect of Naltrexone on Reinstatement of Responding}

Since the concurrent presentation of the $\mathrm{S}_{\mathrm{O}}{ }^{+}$and $\mathrm{S}_{\mathrm{A}}{ }^{+}$ elicited greater, albeit nonsignificant, increases in responding than the $\mathrm{S}_{\mathrm{O}}^{+}$alone, the animals were presented with the $\mathrm{S}_{\mathrm{A}}{ }^{+} \mathrm{S}_{\mathrm{O}}{ }^{+}$stimulus combination during the naltrexone tests in order to allow examination of the effects of the opiate antagonist under cue conditions that elicited maximal levels of responding.
Naltrexone significantly attenuated the reinstatement of responding elicited by ethanol-associated discriminative stimuli. In the presence of the $\mathrm{S}_{\mathrm{A}}{ }^{+} \mathrm{S}_{\mathrm{O}}{ }^{+}$, the mean $( \pm \mathrm{SEM})$ number of responses in rats pretreated with naltrexone was $1.3 \pm 0.6$ in contrast to $5.2 \pm 0.8$ in animals pretreated with saline (Figure $3 \mathrm{~A}$ ). This effect of naltrexone was confirmed by a main effect of "drug treatment" $[\mathrm{F}(1,22)=5.96 ; p<.05]$.

Naltrexone did not significantly affect responding in the presence of the water-associated discriminative stimuli. Mean $( \pm \mathrm{SEM})$ responses after presentation of the $\mathrm{S}_{\mathrm{A}}{ }^{-} \mathrm{S}_{\mathrm{O}}{ }^{-}$in rats pretreated with naltrexone were $2.8 \pm$ 1.6 versus $3.6 \pm 1.2$ in rats pretreated with saline (Figure $3 \mathrm{~B})$, and were statistically indistinguishable $[\mathrm{F}(1,22)=$ 0.5 ; NS].

\section{DISCUSSION}

The results demonstrate that discriminative stimuli associated with the availability of ethanol can elicit and maintain ethanol-seeking behavior after prolonged extinction in rats and, thus, may play a role in relapse to alcohol abuse in abstinent subjects. These findings ex-

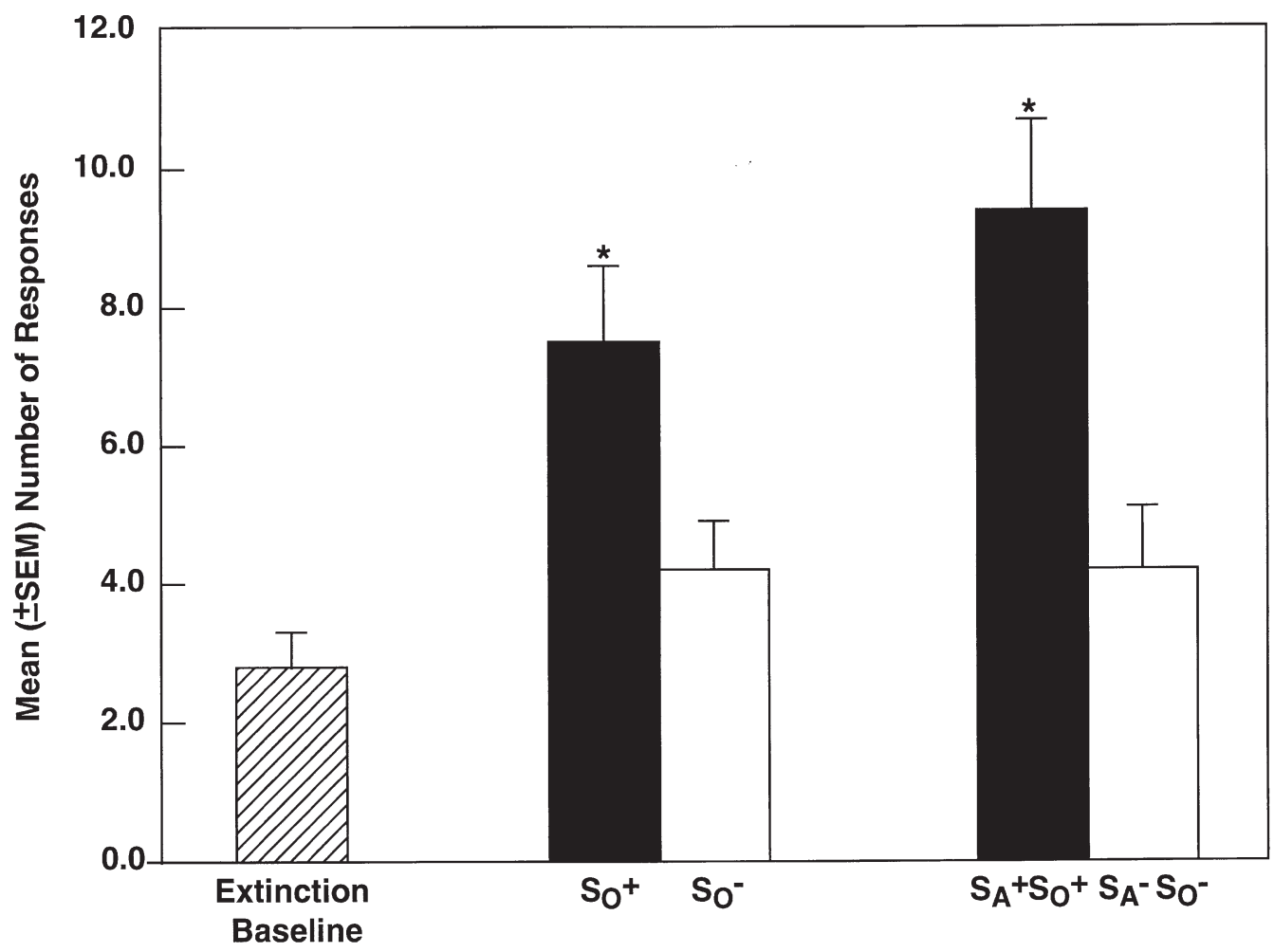

Figure 2. Mean $( \pm \mathrm{SEM})$ lever presses in rats $(n=24)$ during exposure to the ethanol $\left(\mathrm{S}_{\mathrm{O}}^{+}\right)$or water $\left(\mathrm{S}_{\mathrm{O}}{ }^{-}\right)$associated olfactory discriminative stimuli alone, and combined presentation of the ethanol $\left(\mathrm{S}_{\mathrm{A}}{ }^{+} \mathrm{S}_{\mathrm{O}}{ }^{+}\right)$or water $\left(\mathrm{S}_{\mathrm{A}}{ }^{-} \mathrm{S}_{\mathrm{O}}{ }^{-}\right)$associated auditory and olfactory discriminative stimuli. The ethanol-associated olfactory discriminative stimuli, alone or in combination with the auditory cues, reinstated responding in the absence of ethanol availability. The water-associated discriminative stimuli failed to increase responding. ${ }^{*} p<.05$; significantly different from baseline extinction conditions. 

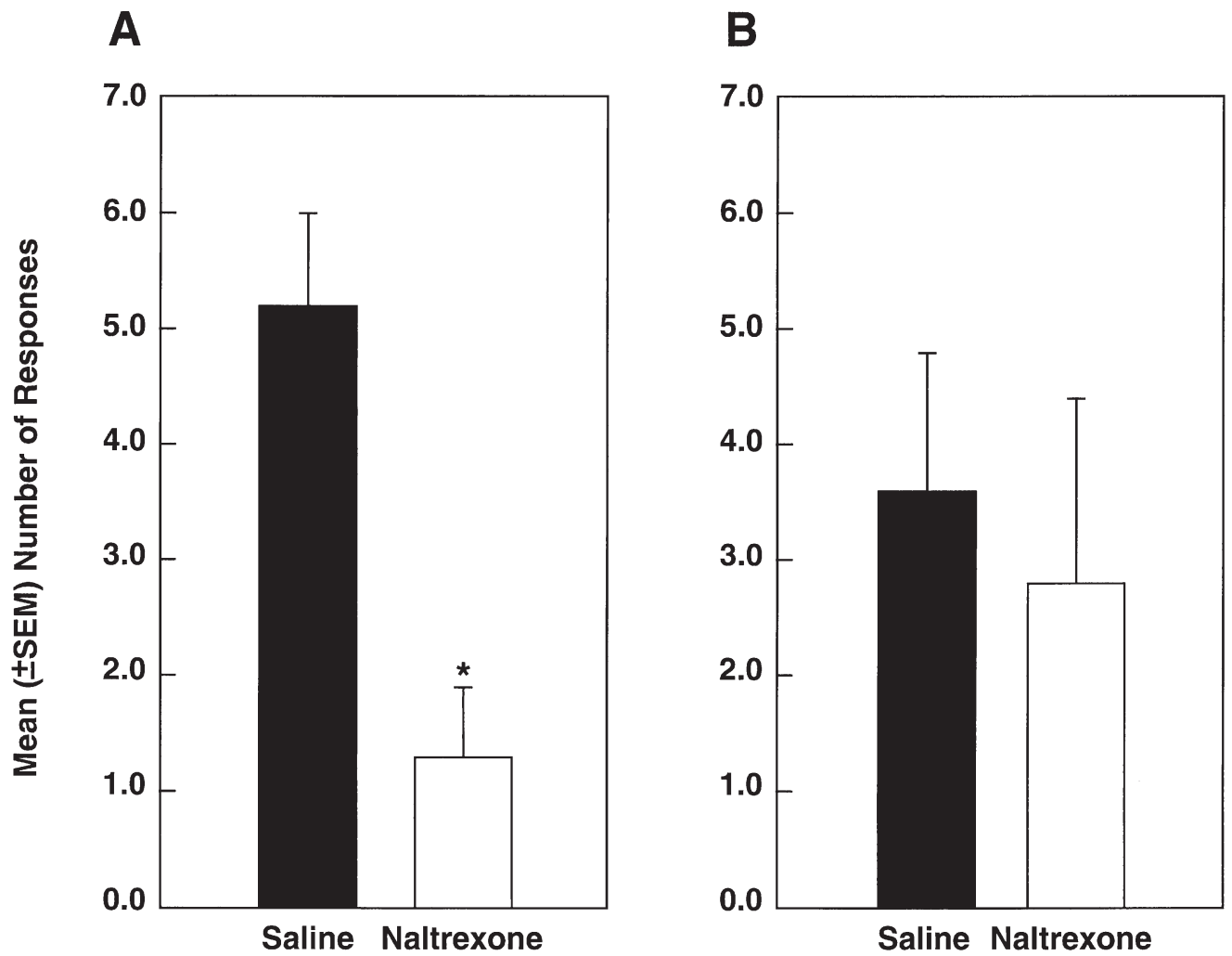

\section{Treatment}

Figure 3. Mean $( \pm \mathrm{SEM})$ number of responses in rats $(\mathrm{n}=12 /$ group $)$ after administration of naltrexone $(0.25 \mathrm{mg} / \mathrm{kg}$; $\mathrm{SC})$ or saline 30 min prior to the session. Rats were presented with the ethanol-associated discriminative stimulus $\left(\mathrm{S}_{\mathrm{A}}{ }^{+} \mathrm{S}_{\mathrm{O}}{ }^{+} ; \mathrm{panel} \mathbf{A}\right)$ and with the water-associated discriminative stimulus $\left(\mathrm{S}_{\mathrm{A}}^{-} \mathrm{S}_{\mathrm{O}}{ }^{-}\right.$; panel B). Naltrexone significantly attenuated the reinstatement of responding elicited by the $\mathrm{S}_{\mathrm{A}}{ }^{+} \mathrm{S}_{\mathrm{O}}{ }^{+}$. There were no statistical differences in responding between the naltrexone and vehicle-treated groups exposed to the $\mathrm{S}_{\mathrm{A}}{ }^{-} \mathrm{S}_{\mathrm{O}}{ }^{-} .{ }^{*} p<.05$; significantly different from saline-treated animals.

tend previous observations of behavioral reinstatement induced by cues associated with other drugs of abuse (McFarland and Ettenberg 1997; Meil and See 1996; Maldonado-Irizarry et al. 1996) to ethanol-related stimuli. Moreover, the reversal of this effect by naltrexone implicates endogenous opioid receptors in the mediation of the motivational effects of ethanol-associated environmental cues.

The cue-induced reinstatement of ethanol-seeking behavior was restricted to an olfactory discriminative stimulus ( $\mathrm{S} \Delta$ ), whereas an auditory $\mathrm{S} \Delta$ did not have a significant effect on responding. This finding is consistent with earlier observations where a tone-light stimulus complex previously paired with the presentation of ethanol failed to maintain lever pressing when presented to rats under extinction conditions (Slawecki et al. 1997). These authors suggested that other stimuli, such as taste and odor, may have been more salient during the conditioning process. However, the failure of an auditory $\mathrm{S} \Delta$ to reinstate responding is in contrast to earlier findings where auditory stimuli associated with cocaine reinforcement successfully reinstated be- havior (Maldonado-Irizarry et al. 1996; de Wit and Stewart 1981).

The failure of the auditory ethanol $\mathrm{S} \Delta$ to elicit robust responding may be related to a lack of salience of this stimulus under the present training conditions where olfactory cues were prominent in the environment. In fact, the presence of olfactory cues while rats were waiting for ethanol or water to become available was inherent to the training procedures, since the odor of the respective drinking solution was able to escape from the tubing supplying the drinking reservoirs within the operant chambers. It appears that these odors served as effective $S \Delta s$ for ethanol vs. water availability and, in fact, superseded the predictive value of the auditory $\mathrm{S} \Delta \mathrm{s}$, which is not surprising in a species in which olfaction is the primary sensory modality (Eichenbaum et al. 1986, 1989; Slotnick and Katz 1974). In addition, the odor of the drinking solutions became available earlier in the training sessions than the auditory cues, a circumstance that may have added to the greater efficacy of the olfactory over the auditory $\mathrm{S} \Delta \mathrm{s}$. Thus, the reinstatement of responding by the ethanol-associated olfactory $\mathrm{S} \Delta$ 
may have been the result of its greater salience-due to its nature (i.e., sensory modality) and relative temporal position-compared to the ethanol-associated auditory $\mathrm{S} \Delta$.

A third and related factor which may have contributed to the efficacy of the olfactory $\mathrm{S} \Delta$ in eliciting ethanol-seeking behavior is that stimuli that are more directly linked to the sensory qualities of the primary reinforcer may be more effective in reinstating drugseeking behavior. It is well documented that "modalityspecific" stimuli are most effective in eliciting subjective reports of craving in cocaine abuse patients (Childress et al. 1987a, 1987b). For example, cocaine "reminders" that can effectively induce "craving" are those that are closely tied to the patient's history of cocaine use, particularly their preferred route of cocaine administration (O'Brien et al. 1992). Thus, the direct sensory association with the primary reinforcer may, in part, explain why the olfactory (but not auditory) cue was effective in reinstating ethanol-seeking behavior in the present study.

Although the ethanol-associated olfactory S $\Delta$ significantly increased responding over the extinction criterion, it did not maintain responding at levels maintained by $10 \%$ ethanol during the self-administration training phase. Nonetheless, the behavioral response pattern elicited by the $S \Delta$ was similar to the typical behavioral profile associated with ethanol self-administration in that responding was distributed largely over the first five minutes of the session (data not shown). In addition, since responding during the reinstatement test was not directly reinforced by ethanol, this behavior would not necessarily be expected to be maintained at the same levels maintained by the primary reinforcer. In a comparable study of cue-elicited reinstatement of cocaine-seeking behavior, responding reached approximately $56 \%$ of the levels previously maintained by cocaine (Meil and See 1996), whereas the total number of responses elicited by the ethanol-associated olfactory $\mathrm{S} \Delta$ in the present study was approximately $30 \%$ of ethanol maintained responses. Thus, the ethanol cue in the present study produced slightly lower levels of responding than a cocaine-associated stimulus in related work (Meil and See 1996). This, however, is not surprising given that ethanol is often a less potent reinforcer in animals than cocaine.

The time-course and resistance to extinction or lack thereof of the cue-induced ethanol-seeking behavior demonstrated here remains unknown. It is likely that repeated exposure to the ethanol cue in the absence of ethanol availability will result in extinction of behavior supported by the cue, although related studies indicate that, in the case of cocaine, resistance to extinction of cue-induced responding can persist for weeks (BenShahar et al. unpublished observation). It remains to be determined whether a similar resistance to extinction can be observed with ethanol.
The introduction of the olfactory $\mathrm{S} \Delta$ during the reinstatement phase was a post-hoc strategy and these S $\Delta$ 's were not experimentally manipulated during the training phase. However, the amount and concentration of ethanol or water deposited in the bedding of the operant chambers during the reinstatement tests matched the average amount of ethanol or water that was typically deposited in the bedding during the training phase as a result of connecting and bleeding the tubing carrying the drinking solutions to the drinking cups in the operant chambers prior to the onset of each training session. Thus, the stimulus conditions during the training and reinstatement phases were identical.

Naltrexone selectively decreased responding elicited by the ethanol-associated olfactory $\mathrm{S} \Delta$. Specifically, naltrexone reversed the increases in responding induced by the ethanol-associated $\mathrm{S} \Delta$ but did not alter responding in the presence of the water-associated $\mathrm{S} \Delta$. Naltrexone decreases ethanol intake in rodents and monkeys (Myers et al. 1986; Volpicelli et al. 1986). More importantly, naltrexone can decrease the frequency of relapse in human alcoholics and suppress subjective feelings of craving and the desire to drink ( $\mathrm{O}^{\prime}$ Malley et al. 1992; Volpicelli et al. 1992, 1995; Davidson et al. 1996). The mechanisms by which naltrexone inhibits alcohol-seeking behavior are not fully understood, but evidence is accumulating to suggest that the efficacy of opiate antagonists to inhibit ethanol intake lies in their ability to block the reinforcing aspects of ethanol that are dependent on dopaminergic activation (Acquas et al. 1993; Benjamin et al. 1993; Gonzales and Weiss 1998). The reversal by naltrexone of the reinstatement of responding by an ethanol-associated cue extends these observations to a role for opioid peptides or opioiddopamine interactions in the motivational effects of ethanol-related environmental stimuli. Furthermore, this finding suggests that the current procedures have predictive validity with regard to their utility as a tool for the evaluation of potential treatment drugs for alcohol craving and relapse.

There is ample evidence that environmental stimuli associated with the availability of ethanol can induce strong alcohol cravings and reinstate alcohol-seeking behavior in humans. For example, in a group of alcoholics the sight and smell of the alcoholic beverage most commonly consumed by each subject elicited the largest change in measures of heart rate, desire to drink, and self-reported withdrawal symptoms (Staiger and White 1991). In another study, cue reactivity such as salivation and the urge to drink was assessed in a group of alcoholics utilizing olfactory stimuli similar to those in the present experiment (i.e., a "water cue" by allowing subjects to smell a glass of water, and an "ethanol cue" by allowing patients to smell a glass of their most frequently consumed alcoholic beverage). It was determined that alcoholics salivated more and reported 
more urge to drink during alcohol exposure than during water exposure (Monti et al. 1993). The significance of alcohol-associated environmental cues also has been documented by findings showing that abstinent alcohol users exposed to an environment resembling a bar worked harder for alcohol and experienced greater subjective and physiological responses than those exposed to a neutral setting (Ludwig et al. 1974).

These clinical findings clearly illustrate the importance of environmental stimuli associated with the acquisition or consumption of ethanol in alcohol relapse in humans. Effective behavioral methods that model "relapse" induced by alcohol-related stimuli may provide useful tools for the understanding of conditioning factors in relapse and their neurobiological basis. Reexposure to previously self-administered drugs has been shown to effectively reinstate drug self-administration in humans and laboratory animals (Stretch and Gerber 1973; Ludwig et al. 1974; Davis and Smith 1976; Meyer and Mirin 1979; de Wit and Stewart 1983; Stewart and Wise 1992; Chiamulera et al. 1995). However, craving or the desire to engage in drug-seeking behavior often occurs in the absence of the abused drug. The present results confirm that ethanol-seeking behavior can be elicited by environmental stimuli in the absence of the primary reinforcer. The present procedures dissociate the motivation to engage in alcohol-seeking behavior from the reinforcing properties of ethanol consumption and, thus, may be useful for investigating the neurobiological mechanisms involved in alcohol-seeking behavior and relapse.

\section{ACKNOWLEDGMENTS}

This is publication number 11186-NP from The Scripps Research Institute. This work was supported by grant AA 10531 from the National Institute on Alcohol Abuse and Alcoholism (NIAAA) to F.W. The authors would like to thank Mike Arends for his assistance in the preparation of the manuscript.

\section{REFERENCES}

Acquas E, Meloni M, Di Chiara G (1993): Blockade of deltaopioid receptors in the nucleus accumbens prevents ethanol-induced stimulation of dopamine release. Eur J Pharmacol 230(2):239-241

Benjamin D, Grant ER, Pohorecky LA (1993): Naltrexone reverses ethanol-induced dopamine release in the nucleus accumbens in awake, freely moving rats. Brain Res 621(1): $137-140$

Chiamulera C, Valerio E, Tessari M (1995): Resumption of ethanol-seeking behaviour in rats. Behav Pharmacol 6:32-39

Childress AR, McLellan AT, Ehrman R, O'Brien CP (1987a): Extinction of conditioned responses in abstinent cocaine or opioid users. In: Harris LS, (ed), Problems of Drug Dependence 1986. Rockville, National Institute on Drug Abuse, NIDA Res Monogr 76:189-195

Childress AR, McLellan AT, Ehrman R, O'Brien CP (1987b): Conditioned craving and arousal in cocaine addiction: A preliminary report. Submitted for presentation at the 49th Annual Meeting of the Committee on Problems of Drug Dependence. Philadelphia, PA, June 15, 1987

Childress AR, McLellan AT, Ehrman R, O'Brien CP (1988): Classically conditioned responses in opioid and cocaine dependence: A role in relapse? In: Ray BA (ed), Learning Factors in Substance Abuse. Rockville, National Institute on Drug Abuse, NIDA Res Monogr 84:25-43

Davidson D, Swift R, Fitz E (1996): Naltrexone increases the latency to drink alcohol in social drinkers. Alcohol Clin Exp Res 20(4):732-739

Davis WM, Smith SG (1974): Behavioral control exerted by an amphetamine based conditioned reinforcer. In: Singh JM, Lal H (eds), Neurobiology and Influences on Behavior, Drug Addiction, Vol. 3. New York, Stratton Intercontinental Medical Book Corporation, pp 209-217

Davis WM, Smith SG (1976): Role of conditioned reinforcers in the initiation, maintenance and extinction of drugtaking behavior. Pavlovian J Biol Sci 11:222-236

de Wit H, Stewart J (1981): Reinstatement of cocaine-reinforced responding in the rat. Psychopharmacology 75: 134-143

de Wit H, Stewart J (1983): Drug reinstatement of heroinreinforced responding in the rat. Psychopharmacology 79:29-31

Ehrman RN, Robbins SJ, Childress AR, O'Brien CP (1992): Conditioned responses to cocaine-related stimuli in cocaine abuse patients. Psychopharmacology 107:523-529

Eichenbaum H, Fagan A, Cohen NJ (1986): Normal olfactory discrimination learning set and facilitation of reversal learning after medial-temporal damage in rats: Implications for an account of preserved learning abilities in amnesia. J Neurosci 6:1876-1884

Eichenbaum H, Mathews P, Cohen NJ (1989): Further studies of hippocampal representation during odor discrimination learning. Behav Neurosci 103:1207-1216

Gonzales RA, Weiss F (1998): Suppression of ethanol-reinforced behavior by naltrexone is associated with disruption of ethanol-induced accumbal dopamine release. J Neurosci in press.

Kranzler HR, Bauer LO (1992): Bromocriptine and cocaine cue reactivity in cocaine-dependent patients. Br J Addict 87:1537-1548

Ludwig AM, Wikler A, Stark LH (1974): The first drink: Psychobiological aspects of craving. Arch Gen Psychiatry 30:539-547

Maldonado-Irizarry CS, Smith D, Koob GF, Weiss F (1996): Blockade of D-1 and D-2 receptors attenuates "relapse" elicited by cocaine-associated environmental stimuli following prolonged extinction. Society Neurosci Abstracts 22:925

McFarland K, Ettenberg A (1997): Reinstatement of drugseeking behavior produced by heroin-predictive environmental stimuli. Psychopharmacology 131(1):86-92

Meil WM, See RE (1996): Conditioned cued recovery of 
responding following prolonged withdrawal from selfadministered cocaine in rats: An animal model of relapse. Behav Pharmacol 7:754-763

Meyer RE, Mirin SM (1979): The Heroin Stimulus: Implications for a Theory of Addiction. New York, Plenum Medical Book Company

Monti PM, Rohsenow DJ, Rubonis AV, Niaura RS, Sirota AD, Colby SM, Abrams DB (1993): Alcohol cue reactivity: Effects of detoxification and extended exposure. J Stud Alcohol 54(2):235-245

Myers RD, Borg S, Mossberg R (1986): Antagonism by naltrexone of voluntary alcohol selection in the chronically drinking macaque monkey. Alcohol 3:383-388

O'Brien CP, Childress AR, McLellan T, Ehrman R (1990): Integrating systematic cue exposure with standard treatment in recovering drug dependent patients. Addict Behav 15:355-365

O'Brien CP, Childress AR, McLellan T, Ehrman R. (1992): A learning model of addiction. In: $\mathrm{O}^{\prime}$ Brien $\mathrm{CP}$, Jaffe JH (eds), Addictive States. New York, Raven Press, pp 157177

O'Malley SS, Jaffe AJ, Chang G, Shottenfeld RS, Meyer RE, Rounsaville B (1992): Naltrexone and coping skills therapy for alcohol dependence: A controlled study. Arch Gen Psychiatry 49:881-887

Robbins SJ, Ehrman RN (1992): Designing studies of drug conditioning in humans. Psychopharmacology 106:143153

Robbins TW (1978): The acquisition of responding with conditioned reinforcement: Effects of pipradol, methylphenidate, d-amphetamine, and nomifensine. Psychopharmacology 58:79-87

Samson HH (1986): Initiation of ethanol reinforcement using a sucrose-substitution procedure in food- and watersated rats. Alcohol Clin Exp Res 10:436-442

Schuster CR, Woods JH (1968): The conditioned reinforcing effects of stimuli associated with morphine reinforcement. Internat J Addictions 3:223-230

Slawecki CJ, Samson HH, Chappell A (1997): Intranucleus accumbens amphetamine infusions enhance responding maintained by a stimulus complex paired with oral ethanol self-administration. Pharmacol Biochem Behav 58(4):1065-1073

Slotnick BM, Katz HM (1974): Olfactory learning-set formation in rats. Science 185:796-798

Staiger PK, White JM (1991): Cue reactivity in alcohol abusers: Stimulus specificity and extinction of the responses. Addict Behav 16:211-221

Stewart J, Wise RA (1992): Reinstatement of heroin selfadministration habits: Morphine prompts and naltrexone discourages renewed responding after extinction. Psychopharmacology 108:79-84

Stretch R, Gerber GJ (1973): Drug-induced reinstatement of amphetamine self-administration behaviour in monkeys. Can J Psychol 27:168-177

Volpicelli JR, Alterman AI, Hayashida M, O’Brien CP (1992): Naltrexone in the treatment of alcohol dependence. Arch Gen Psychiatry 49:876-880

Volpicelli JR, Davis MA, Olgin JE (1986): Naltrexone blocks the post-shock increase of ethanol consumption. Life Sci 38:841-847

Volpicelli JR, Watson NT, King AC, Sherman CE, O'Brien CP (1995): Effect of naltrexone on alcohol "high" in alcoholics. Am J Psychiatry 152(4):613-615

Weiss F, Lorang MT, Bloom FE, Koob GF (1993): Oral alcohol self-administration stimulates dopamine release in the rat nucleus accumbens: Genetic and motivational determinants. J Pharmacol Exp Ther 267:250-258

Wikler A (1948): Recent progress in research on the neurophysiological basis of morphine addiction. Am J Psychiatry 105:329-338 